\title{
Cash, carrots, and sticks: Open Access incentives for
}

\section{researchers [version 1; peer review: 1 approved, 1 approved}

\section{with reservations]}

Joseph Kraus

University of Denver, Denver, CO, 80208, USA

\author{
V1 First published: 31 Oct 2014, 3:263 \\ https://doi.org/10.12688/f1000research.5242.1 \\ Latest published: 31 Oct 2014, 3:263 \\ https://doi.org/10.12688/f1000research.5242.1
}

\section{Abstract}

Each country, scholarly field and institution has developed responses to new scholarly communication systems, and those policies and responses influence the behavior of the scholars within those systems. Over the last couple of years, policy makers and stakeholders in the United Kingdom have thoroughly discussed open access issues. In July 2012, the Finch Report and the Research Councils UK (RCUK) Policy on open access were published. The RCUK, one of the major funding bodies for research in the UK, announced the availability of a new funding mechanism to help researchers at member institutions transition their sponsored work to open access sources. Because the author is more familiar with the scholarly communication situation in the United States, the author interviewed 16 people with international perspectives on scholarly communication issues. This article provides an overview of the discussions with those individuals.

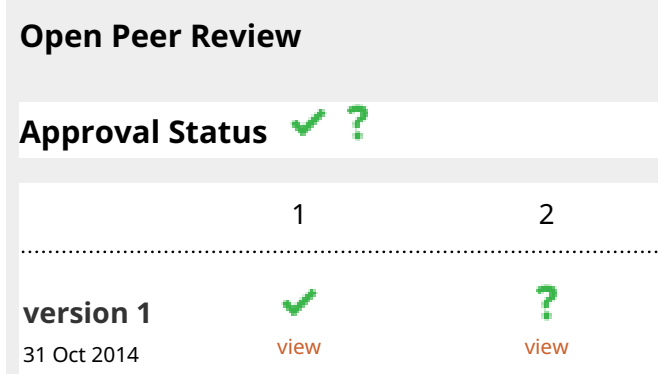

1. Micah Vandegrift, Florida State University, Tallahassee, USA

2. John Dupuis, York University, Toronto, Canada

Any reports and responses or comments on the article can be found at the end of the article.

Corresponding author: Joseph Kraus (joseph.kraus@du.edu)

Competing interests: The author is an open access advocate, and he is involved in the editing and publishing of two open access journals. They are Collaborative Librarianship and the Journal of Creative Library Practice. These two journals are in no way affiliated with F1000 Research.

Grant information: The author(s) declared that no grants were involved in supporting this work.

Copyright: ( $\subset 2014$ Kraus J. This is an open access article distributed under the terms of the Creative Commons Attribution License, which permits unrestricted use, distribution, and reproduction in any medium, provided the original work is properly cited. Data associated with the article are available under the terms of the Creative Commons Zero "No rights reserved" data waiver (CC0 1.0 Public domain dedication).

How to cite this article: Kraus J. Cash, carrots, and sticks: Open Access incentives for researchers [version 1; peer review: 1 approved, 1 approved with reservations] F1000Research 2014, 3:263 https://doi.org/10.12688/f1000research.5242.1

First published: 31 Oct 2014, 3:263 https://doi.org/10.12688/f1000research.5242.1 


\section{Introduction}

With the advent of the Internet, scholarly communication has undergone many changes, and it will continue to change in the future. There are many technological innovations that allow for greater and faster sharing of information and knowledge throughout the world. However, even with technological advances, the peer-review system is still a slow process (Roberts, 1999; Smith, 2006). The tenure and promotion system allows (or even encourages) scholars to be conservative (Murray-Rust, 2008) during this time of change (Cavanagh, 2012). Scholars are rewarded when they publish articles and books with traditional and well-known publishers. The researchers may not be encouraged to submit works to new and different publishing outlets (Rohe, 1998). Hence, some institutions and scholarly fields can be slow to change course when new publishing options become available.

Since the author works at a medium-sized private university in the United States, he is most familiar with the financial and social incentives for researchers in the United States. After reading discussions concerning the proposed policy changes for research funding in the United Kingdom, he desired to learn more about the social and financial shifts occurred there. While much could be learned by reading many of blog posts, reports, news sources, and other content that cover higher education and open access policy in the United Kingdom, the author sought to discuss the matter directly with open access advocates who know more about the situation in the UK. Thus, the author interviewed 16 different individuals who have a greater understanding of the situation in the UK. Ten of the sixteen interviewees were based in the UK or Europe at the time of the interviews. Two different interviewees mentioned the "carrot and stick" approach as an incentive method for changing behavior. In addition to financial rewards (cash) for scholars and researchers, there are a number of other positive (carrots) and negative (sticks) reinforcement methods to encourage greater sharing of research.

There are many issues at play during this time of change. The interviewees were asked how they viewed the policy changes occurring within the UK government, and discussed some other aspects of the scholarly communication system. Many scholars are concerned about the rise of the open access megajournals, such as PLOS ONE. Scholars are investigating alternative ways to measure the use, citation and interaction of content with their readers. "Altmetrics" is becoming the term of art (Lapinski et al., 2013). With new scholarly communication mechanisms, scholars are reinvestigating the issues of journal prestige, the use of impact factors, and the role of tenure and promotion committees. Scholars join scholarly societies, and are concerned about the effect of new publication models on those societies. Lastly, the UK uses the Research Excellence Framework (REF) to assess the quality of research within their higher education institutions (http://www.ref.ac.uk/). Many scholars in the UK are concerned about how the changing policies will affect the assessment process.

\section{Overview of Open Access developments}

For those not familiar with open access principles in general, one should consult the books by Dr. Peter Suber (2012) and Crawford (2011). More recently, Vincent \& Chris (2013) edited the book Debating Open Access for the British Academy for the Humanities and Social Sciences. These three sources provide good overviews of the topic.

Specific to the situation in the UK, Dr. Suber wrote about the movements toward open access in the UK and Europe in the SPARC Open Access Newsletter (2012). However, this covers many of the events through September of 2012, and there have been additional changes to documents and policies since then.

\section{The Finch Report}

In March 2011, the Honorable David Willetts MP, UK Minister for Universities and Science, recommended that an independent working group be formed to investigate "a programme of action and make recommendations to government, research funders, publishers and other interested parties on how access to research findings and outcomes can be broadened for key audiences such as researchers, policy makers and the general public" (http://www.researchinfonet.org/publish/finch/wg/).

In October 2011, the Working Group on Expanding Access to Published Research Findings was set up, and it was chaired by Dame Janet Finch DBE, Professor of Sociology at Manchester University and independent co-Chair of the Council for Science and Technology.

The report from the working group was released on June 18th, 2012, and it had not been modified since its release. The full title of the report is Accessibility, Sustainability, Excellence: How to Expand Access to Research Publications. Most researchers refer to this report simply as the Finch Report (2012).

On July 11, 2012, SPARC Europe responded to the Finch Report (Wellander, 2012).

On July 16, 2012, the UK government announced that it accepted the findings of the Finch Group. (http://www.researchinfonet.org/ government-accepts-finch-proposals/).

\section{Research Councils United Kingdom (RCUK) Open Access policy}

On July $16^{\text {th }}$, 2012, The Research Councils United Kingdom (RCUK) simultaneously published their open access policy document. After the initial policy was published on July 16, 2012, there were a number of times when the policy was clarified or modified to better meet the needs of the scholars. The most recent policy statement was updated on April 8, 2013 (Research Councils UK, 2013). Dr. Mark Thorley, Chair of the RCUK Research Outputs Network, was the lead person from the RCUK who published some of the clarifications to the policy.

\section{Interview questions: summary of responses}

During October, November, and December of 2012, the author interviewed 16 researchers, scientists and scholars who were knowledgeable of the situation in the UK and Europe. Ten of the 16 interviewees were based in the UK or Europe at the time of the interviews. The other six are familiar with the scholarly communication system. In addition to questions that were specific to the Finch Report and the RCUK policy, the author also asked the interviewees about other aspects of scholarly communication. These included the topics of megajournals, journal prestige, society publishing, altmetrics, and the Research Excellence Framework. 


\section{Green and gold Open Access methods}

1) The Finch Report and the RCUK report recently came out. These reports have taken stances concerning green and gold Open Access in the UK. What are your thoughts on the issue of green vs. gold open access policies?

The respondents had a mix of recommendations. While it is clear that many scientists and researchers would prefer that the final published version be the open access version of record, there are many proponents of institutional repositories who would like to see their work get more use and status. The Finch report indicated that the usefulness of institutional repositories was being downgraded. However, it was noted that RCUK policy has wider latitude. While the Finch Report recommended a gold open access route, the RCUK could take a stance that recommends both green and gold open access methods. There was one individual who recommended a third method. This person noted that libraries could be much more involved in publishing research works.

\section{Megajournals}

Solomon \& Björk (2012) describe megajournals as sources that have "very broad scopes. These journals have quick submission-topublication times and only screen for scientific reliability, leaving it to the readers rather than the reviewers to judge the relevance".

Norman (2012) noted that these journals shared a number of features, such as sound science, academic editors, automated and scalable workflows, fast turnaround time, APCs around GBP $£ 1,000$, post-publication promotion, and article-level metrics.

Some scholars are starting to see that the title of the journal that they publish in is becoming less and less important. Researchers are seeing less of a connection between past journal title prestige and the possible future impact through open access readership (Lozano et al., 2012). Thus, researchers are willing to publish their articles in broad-based open access journals that do not have niche titles.

2) PLOS ONE is a well-known large open access journal that covers a broad range of disciplines. Because it has been deemed successful, other publishers have also proposed or started similar journals. What is your opinion of this new type of publication outlet?

Most of the interviewees saw the rise of new magajournals as a positive development. There is space in the scholarly publishing industry to support many megajournals as well as niche journals. In the future, the megajournal will simply be called a journal that happens to have a broad scope and appeal.

\section{"Move the prestige to Open Access"}

As stated in the Finch Report, moving prestige to open access will entail a change of culture.

Section 4 (What needs to be done, page 7) begins as follows:

Implementing our recommendations will require changes in policy and practice by all stakeholders. More broadly, what we propose implies cultural change: a fundamental shift in how research is published and disseminated.
Dr. Michael Taylor (2012) wrote up some thoughts about the Finch Report, and he noted that:

Cultural change is exactly what's needed - not just in how research is published, as noted in the report, but even more importantly in how it's evaluated. In particular, we're going to have to stop assessing research by what journal it's published in, and start looking at the value of the actual research.

Harvard University had noted in this report, "Faculty Advisory Council Memorandum on Journal Pricing", (http://isites. harvard.edu/icb/icb.do?keyword=k77982\&tabgroupid=icb.tabgroup143448) that researchers and authors from Harvard should "consider submitting articles to open-access journals, or to ones that have reasonable, sustainable subscription costs; move prestige to open access".

The concept of asking faculties to move their prestige to open access is interesting, but it entails a cultural shift within hundreds of universities and departments. Because of local circumstances, some universities and colleges may have a harder time requesting their faculty to move their prestige. After the initial question, the author asked for practical advice on how to recommend this path to faculty at his institution.

3) Harvard University has recommended to their faculty to "consider submitting articles to open-access journals, or to ones that have reasonable, sustainable subscription costs; move prestige to open access" (http://isites.harvard. edu/icb/icb.do? keyword=k77982\&tabgroupid=icb.tabgroup143448). The concept of "moving prestige to open access" is an interesting statement to the Harvard faculty authors and researchers. What do you think of this statement?

Some of the interviewees said that the pressure to move prestige to open access sources should continue to come from funding agencies, since those organizations would like to see the widest uptake of the research that they had funded. Other interviewees noted that open access proponents should discuss the issue with lower level researchers and students. Once the scholarly publication system is explained to younger scholars, it will be obvious to them to publish their work in open access sources. However, younger scholars have to live in the scholarly publishing world as it currently exists. Even if several educational institutions issued a statement similar to Harvard University, this would reach a small minority of researchers. This is a collective action problem. Not only do researchers at many large educational institutions have to believe they can move their authority to open access, they have to act on that.

\section{The effect of Open Access on societies}

There are quite a number of viewpoints concerning how the changing scholarly communication ecosystem is going to affect society publishing (Jump, 2013; Shieber, 2013; Morris \& Thorn, 2009). In particular, Dr. Neylon (2012) addressed this topic in a blog post:

With major governments signalling a shift to open access it seems like a good time to be asking which organisations in the scholarly communications space will survive the transition. It is 
likely that the major current publishers will survive, although relative market share and focus is likely to change. But the biggest challenges are faced by small to medium scholarly societies that depend on journal income for their current viability.

However, it should be noted that Dr. Neylon works for PLOS as their Advocacy Director.

4) University presses and many societies are concerned about how the open access movement will affect their financial bottom line. What concerns do you have about open access and society publications?

Many of the respondents expressed a concern for the long term survival of scholarly societies. Historically, scholarly societies have published the highest quality and the most cost-effective research journals. Some respondents recommend that the services that societies provide to scholars be unbundled from their publishing activities. For example, the funding for conference activities should be separated from publishing activities. Several people recommended that societies use alternative funding models, such as a PeerJ model or a SCOAP3 model. Others recommended that more societies could collaborate to save on costs, and use the same publishing platform. Another person recommended that societies could take advantage of open source software such as OJS as a publishing platform. Learned societies have adapted to changes in the past, and they will continue to do so. In the future, the most successful societies will focus on their mission to disseminate research in the most costeffective way.

\section{The rise of Altmetrics}

Altmetrics is a new field of endeavor, and it has been widely discussed in the literature. Several articles (Adie \& Roe, 2013; Eysenbach, 2011; Mounce, 2013; Priem et al., 2012; Baynes, 2013) will provide background reading if needed.

5) Altmetrics is gathering steam as an additional method for faculty to determine the impact of their work (http://altmetrics.org). Do you plan to take advantage of these data for either your work, or for the benefit of your institution or department?

Most of the interviewees see a connection between the measurement of individual research items and researcher impact and altmetrics. All of the interviewees plan to keep up with the research in altmetric systems. Some of the interviewees were concerned with the use of social media mentions as part of an altmetric score. Some also had concerns with the possibility of researchers gaming the altmetric system. However, most understand the limitations of article citations as the only measure of scholarship value. Several interviewees mentioned that researchers publish work that is not in the form of a journal article. Many researchers write computer code, publish data, present conference papers, and more. This non-article work is difficult to measure using traditional citation metrics. With additional data points beyond Thomson Reuters journal Impact Factors, researchers will be able to document readership and the use of their work that goes beyond citation counts. By taking advantage of altmetric measurement systems, scholars who publish in non-elite and nontraditional sources can demonstrate their value as a scholar. In other words, scholars can publish strong work in less established sources and show that the work had an impact.

\section{Impact factors, the Research Excellence Framework (REF), and the Wellcome Trust}

The Impact Factor that is published by Thomson Reuters has been widely used in scholarly circles as a proxy for journal prestige. The higher the number, the higher the perceived prestige of a journal. There is a great amount of research surrounding the manipulation (Yu \& Wang, 2007) and use of the Impact Factor number (Garfield, 2006). During May 2013, about 150 researchers and 75 organizations (Basken, 2013) issued the "San Francisco Declaration on Research Assessment (DORA)". The signers of the document recognized "the need to improve the ways in which the outputs of scientific research are evaluated" (http://am.ascb.org/dora/).

In the UK, there are two major organizations that do not take the Impact Factor (or the perceived prestige of a journal title) into account when determining the quality of published research.

\section{Wellcome Trust Funding Policy}

The Wellcome Trust "affirms the principle that it is the intrinsic merit of the work, and not the title of the journal in which an author's work is published, that should be considered in making funding decisions" http://www.wellcome.ac.uk/About-us/Policy/Spotlightissues/Open-access/Policy/index.htm.

\section{Research Excellence Framework}

Their FAQ section of the REF notes that "No sub-panel will make any use of journal impact factors, rankings, lists or the perceived standing of publishers in assessing the quality of research outputs. An underpinning principle of the REF is that all types of research and all forms of research outputs across all disciplines shall be assessed on a fair and equal basis" http://www.ref.ac.uk/faq/all/.

6) The Research Excellence Framework (REF) in the UK notes: "No sub-panel will make any use of journal impact factors, rankings, lists or the perceived standing of publishers in assessing the quality of research outputs" (http:// www.ref.ac.uk/faq/all/). While this is a valid statement for UK based research evaluation, it would be impossible to get a majority of academic tenure and promotion committees throughout the United States to agree to a similar statement in the near future. Since the UK has the REF, and the US does not, how much is this holding back the US from adopting greater $\mathrm{OA}$ policies at various institutions?

Some of the respondents felt that the REF works for a country the size of the UK, but it wouldn't work for the United States. Some of the interviewees noted that the REF statement concerning journal impact factors and rankings were not believed by many researchers in the UK, so a statement by United States officials may not be believed as well. If some United States educational institutions were to adopt similar policies, it may not 
change the perceived value of elite status journals by researchers in those fields.

Funder policies and financial incentives were mentioned by some of the interviewees. Researchers will follow the money. If funders want researchers to publish using open access methods, then researchers will do what the funders demand to receive that funding. In short, the lack of policy statements by US educational institutions concerning the use of "journal impact factors, rankings, lists or the perceived standing of publishers" is probably not holding the US from adopting more OA policies. This not to say that adopting a policy along these lines would not be taken as a positive step, but there are other cultural factors that are limiting the number of open access policies at US educational institutions.

\section{Conclusion}

The author saw that the UK Government was addressing the open access publishing problem head on, and he desired to learn more about how local researchers felt about the discussions surrounding open access and other scholarly communications issues. After meeting with 16 scholars and researchers, he has come away with a more nuanced understanding of the open access landscape.

There are many ways for researchers to disseminate the results of their research. Some open access advocates favor the institutional repository method, and others favor a gold open access method through publishers. This presents a false dichotomy. There is no "One Best Way" in the path of greater Open Access. Some researchers may wish to summarize their research and post it to a blog. Some researchers may want to synthesize their findings and put presentation slides onto SlideShare. Other researchers might wish to place drafts of manuscripts onto a personal website, instead of using an institutional repository. Different scholars in different disciplines will have different ways of sharing their research with the world. As a librarian, I can let researchers know about the advantages and disadvantages of various open access methods, but in the end, the researcher is the one who will decide what is best for them and their research.

There is not much controversy over the rise of megajournals. Many interviewees see it as a natural step in the progression and growth of scholarly journals as they transition to the Internet.

Harvard University may recommend to their faculty that they move their authoritative prestige to open access, but this policy has not caught the attention of many other administrators at institutions in the UK nor in the US. The interviewees noted that while this is a good idea, scholars must consider other cultural and financial issues as they move their work to open access sources.

There are many sizes and types of learned societies, and they have varying levels and sizes of publishing programs. For the most part, librarians support society publishing because they publish some of the most cost effective journals. But, many of the smaller society publishers are either nonprofit or they have very narrow margins. Thus, they may not be in a position where they can experiment with different funding and publishing models. During the transition to open access publishing, societies will need to carefully examine their mission and focus on meeting the information needs of their members and authors.

Altmetrics is poised to provide a new way for scholars to measure their impact within their fields. Since there are new communication methods popping up all the time on the Internet, scholars will have new ways of reaching different audiences. Altmetrics will help the scholars demonstrate the value of new communication methods to administrators at their institutions.

The REF may state that "No sub-panel will make any use of journal impact factors, rankings, lists or the perceived standing of publishers in assessing the quality of research outputs", but that doesn't mean that most people believe it. There are many scholars who still believe that an article that is published in an elite journal will receive higher status because it is published in a high prestige journal. The perceived prestige and status of different journals and publishers can last for a long time.

To close the article, some insightful closing comments from the interviewees are provided.

"We get the impression that people in the US want open access, but they are not prepared to pay for it". [The US say] 'Let's go for green'.

Some of the supporters of green OA "have a strong anti-publisher rhetoric, and this does worry me at times". "The journals are a key part of the quality step".

"We want a transparent APC market, so we can start to create a functioning market in scholarly communication". "Currently, it is a free market for the authors". "They are not aware of the tough choices that libraries have to make". Researchers should "take more responsibility for the dissemination of their research and understand the costs involved in that". Scholars are also learning that "where they choose to place their publication can limit the access to that research".

"We are close to or at least within reach of several of those tipping points that we have been looking at for quite some time". "Things will run very fast, and probably out of our control over the next couple of years. How do we prepare for the avalanche, as it were?"

"The fundamental problem at the heart of the crisis in scholarly communication is the way in which the peer-reviewed paper has become the main currency for tenure and promotion. This has led to a gross inflation of unmemorable, unreadable, irrelevant and/or pointless papers. It has also led to fraud, to shoddy science and to a commensurable rise in retractions and scandals. Finally, it has led to a plague of for-profit publishers whose primary concern is not scholarly communication, but maximising profit". "In brief, OA is too often viewed as a solution to the problems of scholarly communication, but it is becoming increasingly clear that it could in fact exacerbate these problems, particularly as the research community becomes more and more focused on pay-to-publish gold OA". 
"The policies and procedures that are implemented today concerning new communication systems can have an effect on that future".

"My recommendation is library support for scholar-led publishing as the most cost-effective solution for the future".

"The real surprises are still out there". "Open access is just starting" to get a foothold in the marketplace. "It is possible to make good money off of open access". "Entrepreneurship is important. Entrepreneurs need the freedom to fail cheaply". If we "increase the sample size, then we can increase the numbers of successes".

“I don't think I know where we are going. We are in a period where there is going to be a lot of experiments, some of which are not going to work, some of which may partially work, but that will teach us things". "I think that there are dramatic changes coming to the scholarly communications system". "The main thing I think we need is a willingness to try different things, a willingness to fail, and an attitude of humility. See what we can learn as we go along".

\section{Consent}

Written informed consent for publication of these results has been obtained by each interviewee. The text in the interview sections do not indicate the respondent in order to conform to the IRB request.

\section{Competing interests}

The author is an open access advocate, and he is involved in the editing and publishing of two open access journals. They are Collaborative Librarianship and the Journal of Creative Library Practice. These two journals are in no way affiliated with F1000 Research.

\section{Grant information}

The author(s) declared that no grants were involved in supporting this work. The author received a one-quarter sabbatical in 2012 from the University of Denver to perform this research.

\section{Acknowledgements}

I would like to thank all participants for responding to the interview questions.
Adie E, Roe W: Altmetric: enriching scholarly content with article-level discussion and metrics. Learn Publ. 2013; 26(1): 11-17. Publisher Full Text

Basken P: Researchers and scientific groups make new push against impact factors. Chron High Educ. 2013.

Reference Source

Baynes G: Key Issue - Scientometrics, bibliometrics, altmetrics: Some introductory advice for the lost and bemused. Insights: the UKSG journal. 2012 25(3): 311-315.

Publisher Full Text

Cavanagh S: Living in a digital world: Rethinking peer review, collaboration, and Open Access. ABO: Interact J Women Arts. 2012; 2(1): 1640-1830. Publisher Full Text

Crawford W: Open Access: What You Need to Know Now. Chicago: American Library Association, 2011

Reference Source

Eysenbach G: Can tweets predict citations? Metrics of social impact based on Twitter and correlation with traditional metrics of scientific impact. J Med Internet Res. 2011; 13(4): e123.

PubMed Abstract | Publisher Full Text | Free Full Text

Finch J; The Working Group on Expanding Access to Published Research Findings: Accessibility, sustainability, excellence: how to expand access to research

publications. 2012

Reference Source

Garfield E: The history and meaning of the journal impact factor. JAMA. 2006; 295(1): 90-93.

PubMed Abstract | Publisher Full Text

Jump P: Open access will cause problems for learned societies' journals, accepts Finch. Times Higher Education. 2013.

Reference Source

Lapinski S, Piwowar $\mathrm{H}$, Priem J: Riding the crest of the altmetrics wave. Coll Res Libr News. 2013; 74(6): 292-300.

Reference Source

Lozano $G$, Larivière V, Gingras Y: The weakening relationship between the impact factor and papers' citations in the digital age. J Am Soc Inf Sci Technol. 2012; 63(11): 2140-2145.

Publisher Full Text

Morris S, Thorn S: Learned society members and open access. Learn Publ. 2009; 22(3): 221-239.

Mounce R: Open Access and Altmetrics: Distinct but Complementary. Bull Assoc Info Sci Tech. 2013; 39(4): 14-17.

Publisher Full Text

Murray-Rust P: Open Access in chemistry - thoughts for Thursday. Petermr's blog: A Scientist and the Web. 2008.

Reference Source

Neylon C: The challenge for scholarly societies. Science in the Open. 2012 Reference Source

Norman F: Megajournals. Trading Knowledge. 2012.

Reference Source

Priem J, Piwowar HA, Hemminger BM: Altmetrics in the wild: Using social media to explore scholarly impact. 2012; arXiv.

Reference Source

Research Councils UK: RCUK Policy on Open Access and Supporting Guidance. 2013.

Reference Source

Roberts P: Scholarly publishing, peer review and the Internet. First Monday. 1999; 4(4).

Publisher Full Text

Rohe TA: How does electronic publishing affect the scholarly communication process? J Electron Publ. 1998; 3(3)

Publisher Full Text

Shieber S: Why open access is better for scholarly societies. The Occasional Pamphlet. 2013.

Reference Source

Smith R: Peer review: A flawed process at the heart of science and journals.

J R Soc Med. 2006; 99(4): 178-182.

PubMed Abstract | Publisher Full Text | Free Full Text

Solomon DJ, Björk B: A study of open access journals using article processing charges. J Am Soc Inf Sci Technol. 2012; 63(8): 1485-1495.

Publisher Full Text

Suber P: Open Access. Cambridge, MA: MIT Press, 2012.

Reference Source

Suber P: Tectonic movements toward OA in the UK and Europe. SPARC Open Access Newsletter. 2012; (165).

Reference Source

Taylor M: Thoughts on the Finch Report, part 2. Sauropod Vertebra Picture of the Week. 2012

Reference Source

Vincent N, Chris W, Rita G, et al.: Debating Open Access. London: The British Academy. 2013.

Reference Source

Wellander J: SPARC Europe's response to the Finch Report. SPARC Europe. 2012. Reference Source

Yu G, Wang L: The self-cited rate of scientific journals and the manipulation of their impact factors. Scientometrics. 2007; 73(3): 321-330.

Publisher Full Text 


\section{Appendix 1}

\section{Questions for the interviews}

1) The Finch report and the RCUK report recently came out. These reports have taken stances concerning green and gold open access in the UK. What are your thoughts on the issue of green vs gold open access policies?

2) PLOS ONE is a well-known large open access journal that covers a broad range of disciplines. Because it has been deemed successful, other publishers have also proposed or started similar journals. What is your opinion of this new type of publication outlet?

3) Harvard University has recommended to their faculty to "consider submitting articles to open-access journals, or to ones that have reasonable, sustainable subscription costs; move prestige to open access" (http://isites.harvard.edu/icb/icb.do?keyword $=\mathrm{k} 77982 \&$ tabgroupid=icb.tabgroup143448). The concept of "moving prestige to open access" is an interesting statement to the Harvard faculty authors and researchers. What do you think of this statement?

4) University presses and many societies are concerned about how the open access movement will affect their financial bottom line. What concerns do you have about open access and society publications?

5) AltMetrics is gathering steam as an additional method for faculty to determine the impact of their work (http://altmetrics. org). Do you plan to take advantage of this data for either your work, or for the benefit of your institution or department?

6) The Research Excellence Framework (REF) in the UK notes: "No sub-panel will make any use of journal impact factors, rankings, lists or the perceived standing of publishers in assessing the quality of research outputs" (http://www.ref.ac.uk/faq/ all/). While this is a valid statement for UK based research evaluation, it would be impossible to get a majority of academic tenure and promotion committees throughout the United States to agree to a similar statement in the near future. Since the UK has the REF, and the US does not, how much is this holding back the US from adopting greater OA policies at various institutions?

7) Is there anything else you would like to say concerning open access publishing?

\section{Appendix 2}

The text in the interview sections do not indicate the respondent in order to conform to the IRB request.

\section{INFORMED CONSENT FORM - Interviews}

You are invited to participate in a study that will investigate institutional activities and personal opinions concerning open access resources. The title of the study is "Comparing scholarly communication practices and policies between the United States (US) and United Kingdom (UK) stakeholders". The study is conducted by
Joseph R. Kraus. Results of the study will be used to determine best practices for open access policies and strategies. Joseph Kraus can

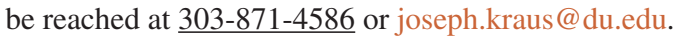

Participation in this study should take about 60 minutes of your time. Participation will involve responding to 7 questions concerning open access resources and policies. Participation in this project is strictly voluntary. The risks associated with this project are minimal. If, however, you experience discomfort you may discontinue the interview at any time. We respect your right to choose not to answer any questions that may make you feel uncomfortable. Refusal to participate or withdrawal from participation will involve no penalty or loss of benefits to which you are otherwise entitled.

Should any information contained in this study be the subject of a court order or lawful subpoena, the University of Denver might not be able to avoid compliance with the order or subpoena. Although no questions in this interview address it, we are required by law to tell you that if information is revealed concerning suicide, homicide, or child abuse and neglect, it is required by law that this be reported to the proper authorities.

If you have any concerns or complaints about how you were treated during the interview, please contact Paul Olk, Chair, Institutional Review Board for the Protection of Human Subjects, at 303-8714531, or you may email du-irb@du.edu, Office of Research and Sponsored Programs or call $\underline{303-871-4050}$ or write to either at the University of Denver, Office of Research and Sponsored Programs, 2199 S. University Blvd., Denver, CO 80208-2121.

\section{Anonymized text from the responses to the questions}

1) The Finch Report and the RCUK report recently came out. These reports have taken stances concerning green and gold Open Access in the UK. What are your thoughts on the issue of green vs. gold open access policies?

"The fact that this was front page news [in the Guardian] it already shows that it is doing a great deal of good because, it raises the awareness level. It allows people to understand what this is".

"There is no one-size-fits-all for everybody. So, by offering both of them, I think there is the best possible balance, that there will be something for everyone". "By suggesting that gold $\mathrm{OA}$ is the way to go, it is catering to academics who don't want to be pushed out of their comfort zone too quickly".

"People get too focused in their own research areas. Researchers will publish their work in niche subject areas". "What works for some people will not work for other people".

"Academics will jump through hoops that their funders make them jump through. That is the biggest stick of all. The funders are starting to act on this".

"Funders will be working on open data next, not just the research articles". 
"There was a perception that the Finch Report was downgrading green OA". "On its own, green is not a sustainable model since it relies on the journals to provide the peer review". "If you don't have the publishers providing the peer review, then green doesn't work anymore". "Green was not seen as a sustainable publishing system".

"Green still has an important role, because of the investment [in institutional repositories] that has taken place in libraries".

"There has been a lot of work in advocacy and in promoting the use of the repositories... and it did feel as if the Finch Report was saying that was just wasted time". "A: the value of the work being done to date was being diminished and underappreciated, and B: the potential for green to act as a catalyst for change was being downgraded".

When the RCUK policy came out, "it looked like the emphasis was on gold. That was the preferred route". "There was no time for a feedback loop between when the Finch Report came out, and when the RCUK Policy came out".

"The RCUK is not downgrading green, it still a valid part of the landscape as one of the alternatives". "But, the way it is worded at the moment, you go for gold, and if there is no gold option, then you can go for green".

When comparing disciplines such as chemistry and physics and their treatment of preprints and post-prints, "there is a huge disciplinary difference in the way the cultures work".

"If you can't get access to the final version, the preformatted [post-print] version might be good enough for you. That is better than no version at all. In the long term, moving over completely to open access journals is where we want to get to".

"The debate in the UK has been around whether or not we are at a stage yet where we can get to full open access journals without sidestepping that transition period. Green open access repositories provides a way" to get there.

"There is a danger that you've just replicated the serials crisis, but on the author payment side of things". "Some journals could say that their APC is $\$ 5,000$, and if you don't like it, then tough".

"I am not convinced that Gold open access is a sustainable model for all of scholarly publishing".

Some organizations in Europe "do not agree with the Finch Report, we need to support both green and gold open access for the immediate future while we see where the transition is going to take us. And, I think that is a sensible approach".

"The RCUK had been charged with looking at the recommendations of the Finch Report to put the policy in place". "The interpretation of the RCUK has been more broadminded". In terms of implementing the policy, "they've taken a broader view that certainly embraces green, and no one is going to be penalized for it".

"The scientific community, the research community doesn't want a chaotic transition from one funding model to the other". "We have to find a way to move from subscriptions to get to alternative modes of payment. At the end of the day, it will be cheaper... but it won't be free, obviously, so the money has to come from somewhere".

"Is the UK out of step with many other countries around the world?" "The European Union is moving towards a green mandate for its next big phase of research funding".

"Both [green and gold routes] are legitimate and potentially effective routes to use to get to an open access end game. I don't favor one over the other. In general, I like the idea of policies that support researchers choosing whichever route works better for them". "The main reason it is hard to pick one over the other, is that despite the amazing growth and terrific progress we've had in creating high quality open access journal outlets, there is not always the perfect OA journal outlet for every researcher in every discipline. It is tough to ask people to wedge themselves into something that is less than perfect for them". "I also think that in different disciplines, and particularly in different geographic regions, such as the developing world, a solution that doesn't have a fee associated with it... may be a more desirable option".

"Making a choice on that is a good way to get in trouble, as an advocate. The people who prefer one or the other tend to spend a lot of energy attacking the other side". "I tend to buy into both, but I think we should hold green to a higher standard than it is currently held. Green, far too often, allows for a crappy version of the paper with no good license to be the acceptable open access alternative, and I think that's bad".

"My ideal world would be one in which green open access means the final peer-reviewed version of the paper under a creative commons license, and it is simply a matter of the author or the journal depositing that into an archive later".

"The idea that an early version of a paper without a copyright license is sufficient for open access-I don't agree with that".

“To understand these different policies, you've got to actually understand the different motivations that have been brought to bear". "So traditionally, a lot of the open access movement had been focused on the public good aspect of giving people access to read things in which they are interested". "A lot of public good thinking has been focused on what do you do with repositories to make things more available to people". "When you look at the actual motivations for the Finch group, the thing you notice is that the motivation is quite different. The government does really care about the public good per se. That is a harsh way of putting it. What the policy is focused on is achieving 
greater return on investment for the public investment in research". "While that return on investment is of more than just economic terms, it includes social returns, educational returns, all those kinds of things, economic return is a big part of it". The Finch report addressed the question, "How do we maximize the value of this public investment in terms of driving innovation, economics activity, and cultural enrichment".

"So the [UK] government has a strong view... that they want to ensure that the downstream users of research both have access and can use it. That is an important distinction between past policy developments which have largely focused on taxpayer access to government funded research. This is very much about 'how do we ensure that things are used and exploited'?"

"The government is focused on the need to ensure not just that research is accessible but also that it is licensed so as to ensure the ability for reuse". "The most efficient way to do that is through a journal based approach to open access".

"The government is quite serious about paying [the publishers] to gain the leverage to ensure the licensing that it wants". "The government could have taken a Harvard style rights retention approach..., but that was not politically achievable". They didn't want to damage the publishing industry, and "that tended to bias the results somewhat".

"Universal gold [with APCs] is probably the only way in which you could make the current system worse". "Because, the journals where we have to publish can charge whatever they want because we have to publish there" to get tenure. "All else being equal, as long as journal rank stays the way it is, as long as we have to publish in those journals, this would be worse than what we have now". "If you have 20 PLOS Biology papers, you will likely lose out to a guy with one or two Nature papers. That is how it is". "The applicant pool has grown so huge" that universities can "ignore basically everybody who doesn't have any of those top publications".

"It is a complex grown ecosystem that is very stable because it is self-reinforcing. Once you've made it there, you feel like 'Well, this is how I got there."'

"Green means that you publish twice. You publish with a publisher, and then you go through the motions again, and then publish a different version [in a repository]. So this means you have extra work, and this takes time that scientists just don't have". "As ethically good as this would be, it just means that" the person will have to do the work twice. "While I support both approaches, simply because they get people to start thinking about the problem, neither of them are really rational solutions. Both of them are neither rational nor sustainable, so there is no real point in supporting them beyond a transitional period that you need to try to build opinion" concerning a rational sustainable solution. "One of them would be to simply have our institutions do the publishing". "There is no point in splitting the literature up into 31,000 journals. There is no point in this day and age. If you want to split it up, you use tags, you use categories, use all kinds of things". "Put it all into one system which is run by the libraries". "Technically, it is easy; politically, it is impossible". "The rational thing to do, which maximizes the benefit for scientists and the general public, is politically almost impossible to do".

"Everybody that I've talked to thinks that peer-review has a beneficial effect, but nobody knows if the benefits are justified by the costs. That is very hard to quantify". "Peer review is not a sacred cow. Let us use evidence to decide whether we keep it".

Concerning post-publication review, "there are many different ways of handling peer review". "Once the scientists are in control, each peer group could decide how they want to do this". "The publishing process could be tailored to the standards of each community". "You don't have to run to publishers".

"Open access policy should be green, not gold". "Good policy provides the direction, the goal - it says what is to be done, but not necessarily how. The how is best left to the people who do the work (some might say the market)".

"Green OA, on the other hand, seems to me to be an appropriate and useful way of seeking to change the system, so long as it is based on self-archiving mandates, and mandates with teeth".

"So whether we get there by the Green or Gold route is much less important than that we get there. I care much more about full BOAI compliance (i.e. freedom to reuse, not just to read) than I do about Green vs. Gold”.

"I suppose in principle I slightly prefer Gold, because that way there is only one definitive version of the article. But publishers have a lot of work to do to persuade me that their contribution (as opposed to the editors' and reviewers' freely donated contributions) are worth $£ 2,000$ a pop, or even $\$ 1,350$ ”.

"The Finch group was a very smart political move to get the publishers signed up to something, and RCUK basically said 'We are doing the same thing' but with subtle differences. The incumbent publishers had no way to fight back because they had already signed up". "The bottom line is... the most effective way to get research in its final published form available in a coherent fashion with the right licensing is to do that through journals". "The mechanisms are in place, you gain the kind of leverage you need and you can make it happen. The flip side of that, if you use the money to pay for leverage, then you want to make sure there is a mechanism for keeping costs down. That is where I think the Finch group really missed a trick in terms of framing repository based open access as a really valuable mechanism".

The Finch Group missed the opportunity to frame repositories as a "transitional mechanism and as a competition mechanism".

"The repository method should have gotten a much stronger airing" at those meetings. Repositories could be used to "provide a different arm for innovation". 
2) PLOS ONE is a well-known large open access journal that covers a broad range of disciplines. Because it has been deemed successful, other publishers have also proposed or started similar journals. What is your opinion of this new type of publication outlet?

"PLOS ONE is a phenomenon, for sure". "The popularity that it has achieved among authors speaks volumes about the desire for researchers to have this type of an outlet". "Business model wise, it has been an eye opener for the publishing community as well as the broader academic community". "Seeing that model break even in the first year, and become so profitable so quickly, I think changed people's perceptions about the sustainability and the long term viability of open access publishing models".

"With the PLOS ONE clones, imitation is the sincerest form of flattery, and clearly, they've hit on a model".

"PeerJ is breaking that mold, and it is wonderful to see a completely different model be introduced to the OA landscape to shake up the notion that it is an all 'author processing fee' world or bust". "The sign of a healthy growing marketplace is diversity of business models and PeerJ's entry to the scene is a really good harbinger on that front".

"It has been a very interesting development, and I think it is encouraging".

"Let everybody else decide if the paper is any good or not because as we've seen time and time again, if you ask the opinion of two or three reviewers, they don't always agree, and they don't always get it right". "Therefore, we have these skewed distributions in all journals in terms of the numbers of citations that the papers get. Journals are playing a funny artificial game trying to manage their reputations, but I think their time is going".

“In some sense, PLOS ONE is a journal, in other ways it isn't. It is just a massive publishing repository. I imagine scaling it up to be just everything". "It would be better for people to make judgments about quality, impact, and importance for the scientific community afterwards because you'll get a better judgment because more people will be involved. If it is open access, then everybody can be involved". "The days of the [traditional] journal may be numbered".

"I am very supportive of PLOS ONE". "We are calling it a megajournal, because we are comparing it by the standards of print journals". "PLOS ONE isn't a megajournal on the Internet, it is just a journal". "I don't think that the niche journals are going to get absorbed...". "The niche journals focus on the very specific topic that the researcher is interested in". Authors "like to have their articles in that context". "There will be space for niche journals on the Internet".

"If we are going to break the hold of commercial publishers on academic research, and I think we are going to need to do that ultimately. Peer review has to change". "More and more of our scholars are creating scholarship that isn't subject to the normal publication process, such as digital humanities, visualizations, all kinds of things that can't be published in the normal way and can't be sent through the outsourced peer review that we've become used to". "Universities, scholarly societies, disciplinary groups are going to need to and probably want to set up other kinds of peer review".

"There is already this explosion of open access publishers, but I am not sure that we will see many journals in that space". "I think we will see a lot of OA journals which are much smaller, but operate under a similar model".

"When you look at different distribution models of content on the Internet, they all have these certain features like an API or they visualize the content in the browser.... If you look at the features that define YouTube or Flickr, or other ways to disseminate content, academic publishing should be copying that". "If there are more [publishers] like that, it is a good thing".

"PLOS ONE has been so successful, it is hard to see why that won't be a trend".

"One of the inefficiencies we have in the system is submit, reject, submit, reject, submit, reject..." "It can take a long time, and you can also get referee fatigue. The reviewer may say 'Hold on, I've seen this paper before. I've already rejected it for journal A'",

Currently, there is no disincentive for authors not send a mediocre paper to high ranking journal. "I am going to send it to Nature and see what happens. It might just slip through". "In the meantime, the comments from the reviewers who rejected the paper have made it better, and the author may submit the slightly better paper" to a different journal.

"As a community, I am not sure that we can continue to pay for these inefficiencies. The library pays for it with the cost of the journals". "Much of the cost of journals goes into rejecting 50-60-80 percent of the manuscripts that are received".

Some journals have a submission fee, whether it is accepted to the journal or not. "That is a really interesting model". "If the paper is accepted, then the submission fee goes toward" the APC. "But, at the moment, it is not very attractive if you are a publisher because your competitors don't have it". "It only works if a lot of publishers decide to do it".

"I actually applaud the rise of the megajournal because it is an example of how innovation in scholarly publishing is actually starting to drive change".

With CC-BY licensed content, "I could see a model whereby others could then harvest or represent papers from across megajournals, and say 'Here are this month's hot papers"' in a subject area. "It could drive some real interesting innovation in the publishing market". 
"I wouldn't be surprised if Elsevier came up with a megajournal". "It makes things easier".

"I am all for PLOS ONE, and the market could support several of them".

"This type of publication is clearly better, both for academic mission and for social good, than closed journals".

"The other thing that no one has a finger on the moment, in terms of the big disruption, is, there are a lot of potential technologies out there for extremely cheap publication infrastructures at essentially zero cost. Storage is cheap. Server access is cheap, and there is some pretty good, if not good enough open source software out there for the hosting and management of journals". "The challenge they have is that it doesn't scale out. To build something that is on the level of a PLOS ONE clone, you have to invest a lot to make sure it still works" at a larger scale. "You don't do that at wordpress. It just isn't going to happen".

"Which happens faster? Do things like OJS and Wordpress become good enough so that people can just throw things up on a server and get things running quickly for themselves, and 1,000 flowers bloom, and once those flowers have bloomed, someone thinks, oh god, we've got to bring it all back together. Or,... someone builds something that does scale out, and it is really, really good, and then lots of people adopt it, and then there is consolidation". "The end result is the same either way, there is a lightweight scalable infrastructure that makes it very easy to run journals at relatively low cost". "Both will be in competition, which one gets there first?"

"We [need to] reassess the process of peer review completely, and we rethink what we want". "That turns the economics upside down, it turns the process upside down, the technical needs, the social requirements, the tools, the whole thing". "My gut feeling, having argued for that over the last five years, is that it isn't going to happen quickly". "What will happen first, is there will be a rebuilding of the technical infrastructure".

"The peer-review at PLOS ONE is as harsh as it is anywhere. What's lite, and indeed completely absent, is selection by trendiness and sexiness. Which is exactly as it should be. We are scientists, not marketeers. (sic)"

"So I am keen to see many other venues with the same approach. That's important because, as good as PLOS is, we don't want to see a monoculture develop, not even a PLOS monoculture".

"One important point to note about PLOS ONE is that it accepts all sound science. This just makes sense; the reason journals have high rejection rates (now seen as a badge of quality) is because in the print medium you can only fit in so many articles. This adds considerable waste to the system (rejected articles are usually still published, it's just that they tend to go through several rounds of review rather than just one). It's good to see competitors, too".
"Simply put, they are probably not radical enough. They seek to marry the traditional journal model with one that would seem to imply a post-publication peer review world, but end up in an unsatisfactory midway position".

"I think it's a good move. For a long time now it's been clear that we don't need 'journals' in the traditional sense. The Web and good search services can do the job journals do. People argue that journals are needed to provide a stamp of quality, or to create a recognised hierarchy of quality". "Personally, I think this has been very damaging in many ways over the years and a move to database publishing like PLOS ONE is welcome".

3) Harvard university has recommended to their faculty to "consider submitting articles to open-access journals, or to ones that have reasonable, sustainable subscription costs; move prestige to open access" (http://isites.harvard. edu/icb/icb.do? keyword=k77982 \& tabgroupid=icb.tabgroup143448). The concept of "moving prestige to open access" is an interesting statement to the Harvard faculty authors and researchers. What do you think of this statement?

"We are in this intermediate phase where it is pretty clear that open access is going to become the distribution mechanism for vast majority of scholarly research". We are still not sure "how that is going to play out in specific deals, in specific institutions, and specific sectors" of research. "It is easy to make this argument for prestige in open access in the life sciences or in physics because you've got SCOAP3 for physics, and you've got PLOS in the life sciences". "For the humanities and the social sciences, it is kind of hard to say 'Publish in a prestigious open access journal' because there aren't very many". "There is no money in some fields for article publishing charges. If you don't have any funding other than your salary, then you don't have a pie from which to cut a slice to pay for an upfront charge. That makes it harder to have this one-sized-fits-all policy that says 'Just publish in a prestigious open access journal"'. "What we need is an ecosystem of open access that is a little more sustainable, and it needs to be flexible across sectors and fields. In some places APCs are going to work really well". "In some places it could be green, but green has to result in quality and true open access content". "I am not sure that this process can be accelerated, and I am not sure that that is a bad thing". "I think that giving it time to evolve may result in it having the right biodiversity that we need in the market".

One of the things that Harvard was saying was that "We need to get over this cultural logjam, that prestige only resides in a handful of subscription access impact factor-ranked journals". "Harvard, with its perceived status, is a great spot to start the discussion of saying, look, 'prestige is in the eyes of the beholder' and we are actually the folks creating the system of prestige and living by the system of prestige. So, if we really lead the charge in terms of voting with our feet and saying we believe prestige can rest in open access journals, equally or even more so than in subscription access journals, then this is something that we have an obligation to do". "It is easier for 
Harvard to start there, but once that snowball gets rolling, the conversations start happening". "Why are we judging this journal by its business model rather than by the actual quality of the articles that are in the journal? That conversation gets really interesting really quickly, and this is something that all schools can participate in". "The questions concerning article level metrics also come into play". "All schools, not just Harvard, really have an opportunity to drive the prestige conversation and the change in perception of what is impactful, what is meaningful, and what is high quality in terms of research output".

"The commercial publishers don't have the power, the universities have the power". "In two very radical steps, universities could completely revolutionize the scholarly communication system. One would be to claim work for hire over all of their publications (I don't actually advocate that), but they could do it and license the works back to the faculty members in very broad terms". "Second step is to evaluate in a different way. Stop confusing prestige with relevance". "Just because an article is published in a high impact journal, it does not mean that it is relevant. The journal impact factor is at the journal level, not at the article level. The data for the journals are aggregates". "Now we have the ability to assess scholarship on the article level". "University promotion and tenure committees should insist on article level metrics, which would basically require open access. And, that is not so radical".

"Institutions need to take some responsibility for moving from evaluating prestige, to evaluating actual quality and impact".

"There is a difficulty in moving that up from anecdote to policy because a lot of policy makers want to buy into the established metrics".

Universities want to increase their rankings in the US News and World Report or the Times Higher Ed rankings. "I haven't seen anybody yet say that the strategy for doing that [to move higher in university rankings] is to adopt an open-access policy".

“"Moving prestige' entails the perception of a financial risk" for the researcher. "I can move my prestige, but that might mean that my department will get less money next year. It has not been causal, but people believe it to be causal".

"The reason researchers aim for the top journals is because the journal they publish in is a shorthand for the quality of the science that they have done. So, that is why they do it".

"If no one cites your Nature paper, what is the use of having published it?"

"One would hope that as the open access journals get to be more prestigious, then publishing in PLOS Biology is as good as Nature".

"If the leaders on campus could recommend Open Access to the lower level faculty, then it just becomes the norm". "That is what we do now. We publish open access because scientifically, that is the best thing to do in terms of public value for the money". The focus on the impact factor "is a major sticking block, so I would like to see all universities adopt an open access mandate for all of their research—at least have a repository, a green route to open access".

The spouse of one interviewee gets letters from university administrators saying that he/she needs to publish in journals that have "an impact factor higher than five".

"Prestige is something that comes from a community itself. It is an intangible thing that is very difficult to pin down". "Prestige fundamentally is money. Money turns into prestige pretty quickly. When you start the process of saying 'this is how we determine funding' and you have statements right from the top saying 'We don't care about the journal, we care about the quality of the work, the importance of the work, or the influence of the work,' whatever it might be, that becomes an important thing". "A very large part of it is top down. The other part of the prestige argument is bottom up".

The uptake of Open Access could be the same as the bell curve for technology integration. There are a small number of early adopters, a large number in the middle, and a small number of late adopters. "The incumbent players are configured in such a way that it is essentially impossible for them to innovate in a disruptive fashion". "The question becomes one of how do you pull that entire bell curve along, and one of the things you learn about that process is that the one thing you don't bother doing at all is to talk to the late adopters. They are simply not worth talking to". "This is part of the thinking about how we advocate for open access. We have to move beyond the 'this is something we should all do' which is how you get the early adopters, people who want to do it because it is the right thing to do, and we have to speak to this mainstream of people about why it is important for their future, that they will get more citations, or whatever the story might be. There are lots of different pieces of functionality that we can offer them".

"The people at the back end who happen to be senior researchers, heads of departments, are exactly the people that we just shouldn't bother with at all because it is a waste of time talking to them. So, what we need to be doing is talking more to younger researchers and students, just talk about this as though it were normal. It is just obvious that it should be this way. They become the early mainstream. They want this because it is obvious that it is the best thing to be doing". "It is obvious to them that if people can't read their research, then they are wasting their time. That kind of logic follows very clearly".

"People talk about prestige, but what they really mean is the ability to earn money, the ability to bring in research income". The institution can "pick out and celebrate those things that are going well. Once the institution starts saying 'this person is doing something really great' that's all it needs to be is a story about something that happened or worked well". "Those kinds of things build a momentum up internally, they build up a culture internally". When talking to Deans and vice presidents, they 
can see that this will provide "better performance on the kinds of metrics that they are looking at". And that "funding policies are shifting to respond to that, so they can be ahead of the curve or they can be behind the curve, and that is an interesting option to put before a president or a vice president of a university".

As a scientist, "the choices and possibilities that we have to influence the publishers are fairly limited, which is one of the reasons why we should cut the ties with them".

"We need to convey to job-search, promotion, tenure and granting committees that open-access publications ought to count for much more than paywalled ones".

"The bottom line is, if a paper is behind a paywall, it's not really published. The academic community is less able to benefit from it; that is even more true of the broader population, which in most cases funded the work".

4) University presses and many societies are concerned about how the open access movement will affect their financial bottom line. What concerns do you have about open access and society publications?

"Some authors in the sciences view the society journals as a third option. The first options are the high profile journals like Nature, Science, and Cell, the second option is a megajournal like PLOS ONE, and the third option is the smaller society journal".

"The humanities situation is perplexing in a couple of different ways". "In the humanities and the social sciences in the UK at least, there is a much stronger sense that the money that runs the existing journals is just growing on trees". "It has been difficult to get people to come to grips with the fact that those journals are being funded out of the public purse". "There is a much stronger culture among the humanities and some parts of the social sciences that these are people who work alone, often work at home, and to a much greater extent, they feel like they are lending their work to the institution". Some humanities scholars "have much less identification to the institution".

"Some of the humanities journals could consider being funded using a SCOAP3 like system". "SCOAP3 may work because it is a tightly bounded community".

Other models and options are available. SCOAP3 is one option. "The Royal Society of Chemistry is another option". "Keep paying us the subscriptions, and we will give you a voucher in exchange, and we will manage this as a transition process".

"In the past, many societies had high revenue streams. There is no guarantee that that will continue. It could go away and not come back". Societies may need to "develop new lines of revenue". "Entrepreneurs could help societies make the transition". Some societies could consider using "PubMedCentral as a publishing platform". There is "no need to build the technology layer underneath" the system.
"It is definitely a concern for some of the smaller societies who are single journal publishers". "The trend of the megajournal is the most concerning" Societies "could consider using the hybrid model as a transition strategy". This "option to select open access and to manage the transition by balancing article submission fees with subscription fees over a reasonable period of time is a palatable and manageable transition strategy" for some of the smaller scholarly societies. "I worry that the time that is left for the strategy to be viable is running out, because of the advent of these megajournals, so many authors are opting to submit their articles to these large open access outlets. I worry that the societies that have not yet made a move towards offering some type of an open access solution, those authors are going to be siphoned off, and the demand for the society journal might lessen".

There are many good models with Oxford University press being successful, the optical society of American being successful. "We use those exemplars and say this is one way to do it that really does mitigate your risk because you don't reduce your subscription price until you have that OA uptake, and you know what the demand looks like in your sphere".

"They just need to find a way to do it. They could just start creating gold open access journals, and move the costs from subscribers to authors".

Subscriptions journals use "a funding mechanism that is going out of fashion with the rise of the internet". "We've seen throughout history that the free market will not support industries that become obsolete". "There is not a lot of money to be made making candles these days, compared to a hundred years ago, because of the light bulb". "This is the sort of thing that happens, and it is happening to the publishing industry".

"Some publishers have been making huge profits, so there are savings to be made by eating into the profit margins".

"Scholarly societies are in a better position to transition to OA than commercial publishers like Elsevier". "Elsevier still has to pay shareholders and such, while societies do not. Smaller societies may be able to get a better handle on their costs". "The first thing any group would need to do is to figure out what it actually costs them to publish". "We (libraries) are having this acrimonious debate with commercial publishers who are always telling us about all of their costs, but we can't actually pin those costs down very often".

"Societies started working with traditional publishers in order to make themselves more sustainable".

"Societies have adapted in the past to stay afloat", and they will continue to do so.

"The bundling issue is something that Open Access is going to disrupt". "Publishers are coming out with innovative models because they have to adapt". 
"It is very hard for them". "They should be looking to reduce their costs". Societies could consider moving their content to a system like "OJS which would allow them to publish very, very cheaply". "Some of that overhead could be pooled" between different societies.

The past is not a good predictor of the future. Some societies see that moving to open access is a rocky road, and they don't want to go down that path. Because of the big deal that larger publishers have implemented, the smaller society "publishers face a very, very rocky road with the subscription model, fighting for a smaller and smaller percentage of the library budget, or a rocky open access road". "They need to look at both of those roads and weigh the risks and the opportunities". A third road is to partner with a larger publisher which then incorporates the title within the big deal, but then the society "may lose independence".

Societies could "also see that open access publishing can be profitable". "There is money to be made in open access".

"Societies should allow researchers to provide green OA as a route to open access. This will provide more exposure for their journals and articles".

"Some societies are perfectly adaptable to change, but they just don't want to change because they see the subscriptions as a cash cow".

Instead of the printing press, "imagine if the cash cow of the society was the pony express or the telegram, would you then think that this would be a valid argument for keeping the pony express running?" "The way publishers do this is outdated and costly". Concerning library subscriptions to society publications, "one could make the argument that this is really unfair subsidization, and that the societies should actually try to find other revenue streams, maybe those that are better tailored to the community that they serve".

"If it comes to a choice between the society thriving at the science's expense or vice versa, then the science has to be the winner every time".

"So far as I am aware, university presses were struggling long before open access had acquired much in the way of mindshare, and the causes of their pain surely lie elsewhere. Learned societies may indeed feel threatened by open access. But if they do, surely that is because they have been treating journal publishing not as a service to the scholarly community, but as a cash cow. They need to refocus on their original mission, and not assume that this can be funded from their journal publishing programme".

"Societies have a mission to serve the interests of their community. Hampering access to research information is the exact opposite. There are some excellent examples of visionary, able societies doing their job well and there are many that are not. I'm afraid the future is not bright for those that won't adapt.
There are ways for societies to lead this movement, but most of them don't have the skills or vision to take up the challenge, sadly".

"Those goals--spread of information; density of conversation-are what matter. If a new, better way to spread information or support conversation appears, we in the academy should adopt those ways, because they are in keeping with our goals. If existing journals and societies have structured themselves around older and now worse ways of doing things, what we cannot afford to do is let them preserve the problem to which they happen to be the solution".

5) AltMetrics is gathering steam as an additional method for faculty to determine the impact of their work (http://altmetrics.org). Do you plan to take advantage of this data for either your work, or for the benefit of your institution or department?

Concerning the wider question of measuring the usage and reusage of research, "I think it is going to expand, and it has a long way to go before it reaches any sort of an equilibrium. At the moment, there is so little that we measure". "The interesting question is the way that what we can measure couples to what we think we want to measure". "When people start to measure something it becomes important, that is not necessarily because it is a good measure of anything, but because that is what is being used". Altmetrics "is something that we can guide as a community in the right kind of direction".

"Is this an open access tool or not? That is an interesting question?" "The principle is a general one that if we are going to measure things about science, we should be measuring the articles, the people, and the work, not the containers".

"The Impact Factor was better than nothing". Integrating altmetrics into the research evaluation process is "inevitable". "Choose the kind of impact you want". "Different departments will want different metrics".

"It is one of the most interesting movements to come along in a long time. We view it as a little bit of an outgrowth of the open access movement, that the article level metrics are growing up around open articles. I think it is an incredibly promising route to help us introduce more granular ways to capture real information about the full story of the impact of individual articles and individual author's works. We've been so dependent on the impact factor as a single metric which actually doesn't tell us anything about an individual article or an individual author, it tells us something about the journal that they published in". "This is something meaningful to them [the faculty and researchers on campus]. These metrics are a way for them to paint a much fuller picture about who is using the outputs of their research, how it is being used. It lets them tell their story in a much deeper and fuller way". "They are very interested in then how can they publish in an outlet that is utilizing these metrics and on the flip side of that, we are hearing from library directors on a lot of campuses, asking if we can come in and 
talk to administrators who are responsible for doing the evaluation of researchers on campus, and they are hungry for indicators that actually tell them something new, and more than an impact factor". "There are tons of unanswered questions about what is it that these metrics that we are beginning to introduce are telling us. How trustworthy and valid are they?" "It is super exciting to see this real possibility to have these new indicators to put into the mix in some way".

"In each of the indicators, we have the ability to drill down and find out more about who is downloading the article. For tweets, it is the same thing, ten tweets on an article, that number may or may not be impressive, but if seven of those ten tweets [concerning a malaria paper] came from the WHO or the CDC or people who are highly regarded researchers in that discipline, the identity of the people who are using your work will be meaningful, and that can be reported in some way".

"The global reach is something that administrators are interested in". Concerning blog posts about articles, "If it is a scientific or research oriented blog, that may be of great interest. If it is a general interest blog, that is also kind of nice". Administrators "like the press, press is good".

"It is very early days, and nobody really knows what it is going to look like". Concerning use data from Mendeley, "there is value in capturing that sort of data". "I would imagine that the buzz there would probably capture" something similar to what the paper might get in the number of citations over the next couple of years. Mendeley would be a better comparison than shares on Twitter, since Twitter "is not necessarily a good indicate of scientific quality. And, plus, I would imagine Twitter is a much more public forum, and therefore, it will attract interest" because of the popularity of the topic, not because it is important research. Tweets can be positive or negative. "Just measuring the noise around a paper isn't good enough. You want to look at downloads, you want to look at discussions in a community that you trust".

"Anytime you try to measure something, you are perturbing the system, and people will be tempted to game it. I am sure we can be clever enough to stay ahead of that".

Will altmetrics help people move away from using the impact factor as an evaluation tool for people or specific articles? "You can make that argument with the data that we already have without altmetrics, and it hasn't worked". "The large majority of the articles [in the high impact journals] are not cited any higher than any other article". "They know that journal rank is a psychological phenomena, a figment, it doesn't really exist".

"They are extremely important. They have to be the wave of the future in evaluating scholarship because of all of the digital scholarship and because they offer us a much better picture of the actual impact of a particular piece of scholarship".

"They really appeal to the ego of academics after all". The researcher can find out "who is actually looking at my work; I've never been able to know that before". With geolocation mapping, "It doesn't tell you who, but it tells you where". "One of the things that has really impressed them [researchers], is beginning to think about uses of their work outside of what they see as their normal channels".

Some researchers might say that "my work is so complex and specific, that only 25 people in the world understand it, and I know who all of them are". "One of the exciting things is to help people get past that view, to show them where their readers might be". Altmetrics can help faculty find "the unexpected readers of their work". "Most people are really excited by that, so I think that there is an educational task there".

"Related to the Altmetrics side of things... I don't know that we are going to continue to judge journals as a whole".

"If you have a dataset that is getting more citations than the article, then [the researcher] should be getting credit for that".

"The publishers that cater to the research needs on that level [with more altmetric data] will be the ones that survive".

"In the UK, we are going to be looking for those sorts of measures more and more" when "the funders are asking what sort of effect is the research having?" "The more the variety of altmetrics we have, the better from our point of view. As you get more and more of them, it gets harder to put them back in the bag".

When researchers are evaluated, it used to be done only on the impact factor. "We are going to move to a situation where [the evaluation process was] easy and wrong, to a position where it will be difficult but correct".

"We are not going to shut Pandora's box on this".

"It could allow for more [journal publishing] competition because it might help to break down this innate conservatism" among researchers. But, at present, "there isn't much understanding of altmetrics".

"If you have to have a number to judge the paper by, then use its own citation count if you must-not the citation counts of other papers that appeared in the same journal. And judging a researcher by the IFs of the journals that her papers appeared in transcends the merely idiotic and achieves the level of moronic".

"I have serious concerns about the rush for AltMetrics, particularly AltMetrics based on social media. Before anyone even begins to think about using such metrics for assessing the work of scholars, much work needs to be done. For example, I argue that it is reasonable to hypothesize that any AltMetrics based on social media (whose work is tweeted, promoted on Facebook, etc.) is likely to reflect and amplify existing social biases".

It "should not be used for assessing the work of scholars".

"In general I applaud the altmetrics work and aims. We need to move away from poor, dated indicators and develop new, meaningful ones". 
Altmetrics "provides a more nuanced and refined way to assess the nature of someone's work".

"I'm impressed by the work that is being done [in altmetrics]. I recognize the problem that we have with the current model of journal impact factors. In our stance, we regard the value of the paper as opposed to the value of the journal it is placed in. If altmetric tools can demonstrate the value of the paper more effectively, then I think that is a good thing".

6) The Research Excellence Framework (REF) in the UK notes: "No sub-panel will make any use of journal impact factors, rankings, lists or the perceived standing of publishers in assessing the quality of research outputs" (http:// www.ref.ac.uk/faq/all/). While this is a valid statement for UK based research evaluation, it would be impossible to get a majority of academic tenure and promotion committees throughout the United States to agree to a similar statement in the near future. Since the UK has the REF, and the US does not, how much is this holding back the US from adopting greater $\mathrm{OA}$ policies at various institutions?

The interviewee has empathy for scientists "who placed their bets on a structure that doesn't work very well". "They resist fads, and they move slowly on major decisions". "We are in the middle of a meaningful change in the scholarly publishing business". "This isn't what they [the established scientists] signed up for". "The real surprises are still out there".

"In the UK, the Wellcome trust does not take the impact factor of the journal into consideration". However, "some people don't believe that the REF guidelines are followed".

"If you are not an expert in that field, then it is quite difficult for you to judge whether the work is good or not". With eLife, "for each paper, they are going to write a lay summary". "That would enable people outside the field to get a sense of the quality of the work". "People are not going to drop the shorthand [using the journal title or publisher name as a proxy for prestige] unless you provide them with an equally easy shorthand" for determining the quality of an article.

"How do you change hundreds of universities tenure and promotion policies? Answer: Slowly". "Funder policies will help for a lot of universities". "A lot second tier universities that have a research component are trying to amp that up for obvious reasons". "Funder policies will begin to drive changes". When tier one universities start to change their policies, it will drive some changes at tier 2 universities and even small colleges. Change will occur "when the faculty begin to create scholarship that is simply not amenable to traditional publication and to traditional impact factor evaluations". "That kind of work... is going to trickle down through the academic world and more and more tenure and promotion committees are going to be confronted with genuine scholarly production that they need evaluate, and they can't rely on an impact factor or the prestige of a journal title". "Change is going to be slow".

"In the UK, we are obsessed with this thing called the Research Evaluation Framework". "Basically, this is a way the government decides how to split money between universities based on how successful they are in research". "For the past 20 years or so, the funders have said, it is the value of the research; it doesn't matter where you publish". Even though that is what is said, "Everybody believes it is where you publish. Everybody you talk to, every researcher says 'of course they say that'" but they still want to publish in the high impact and prestigious journals.

"There has been a real pressure in the UK to make sure you publish" in the prestigious journals because "there is the perception that will directly feedback to the amount of research income you get in the future".

"That view has been an inhibitor [for researchers in the UK] to move to open access". "Most open access journals are new; they don't have the same prestige levels. They have sort of a natural disadvantage to start with. But, that is changing now".

Using impact factors to judge the quality of individual articles is "exactly as rational as high-school kids judging their classmates by the label of the clothes they wear. We're scientists. We're better than that".

"The REF is not all honey and spice. It's had some very perverse consequences over here, as has the Australian version, and I wouldn't recommend the US goes down the same road in quite the same way".

"It is unfortunate that a lot of research is evaluated based on the container (the journal) and the not the article itself. I don't see that this will change in the near future".

"There is a potential driver for this in the UK". With the REF, "one of the factors that is being put into this, and it is pretty controversial, is something called "impact." This is different from impact factor. One could show that the research had impact in the wider world by noting "that it had been picked up by the Times or the Guardian". "Other impacts would include having your work mentioned in a briefing paper about education policy, or if you were invited to talk about your research on a local radio program". "These are altmetric types of things". "It can be part of the narrative describing your impact". 


\section{Open Peer Review}

\section{Current Peer Review Status:}

\section{Version 1}

Reviewer Report 27 November 2014

https://doi.org/10.5256/f1000research.5589.r6615

(C) 2014 Dupuis J. This is an open access peer review report distributed under the terms of the Creative Commons Attribution License, which permits unrestricted use, distribution, and reproduction in any medium, provided the original work is properly cited.

\section{John Dupuis}

Steacie Science \& Engineering Library, York University, Toronto, ON, Canada

\section{Suitability of Title}

The title should probably mention that the article was focused on the situation in the UK.

\section{Does Abstract Accurately Summarize Article}

Yes, but may have to change if the article changes.

\section{Review}

Most of my concerns with this article has to do with the demographics of the interviewees.

The author does not clearly specify how the interviewees were selected. For example, how was the pool of potential interviewees created? Within that pool, how were the actual interviewees selected? Was it random or where there criteria involved?

Even taking into account the confidentiality of the interviews, it may have been possible to be more specific about demographics. Were all the interviewees scientists or were some publishers or librarians or others? How do those categories break down? What was the rationale for selecting non-UK interviewees for learning more about the situation in the UK? Were the interviews conducted by phone, email or in person?

Some other issues:

In the summary of responses, while I appreciate that the various responses are summarized and digested, I also think there are numerous opportunities to be more specific in how the responses are coded. For example, the words such as "many," "most," and "some" are used frequently. The message of the article would benefit from more exactness. Is many 5 or 6 ? Is most 9 or 15 ? Some summaries could easily have benefited from charts or graphs. 
Related, the text of the interviews is extremely rich. Even given that the article is a Research Note, the summaries of responses could have reflected that richness better.

I appreciate that the raw text of the interview responses is available to us. However, it would have been nice to code the responses in such a way that readers could track the various responses by interviewee. For example, S1, S2, etc, for Subject 1, Subject 2, etc.

The material in the conclusions was perhaps a little too much on the summary side and could have benefited a little more in terms of discussion and perhaps what further research is needed.

Competing Interests: No competing interests were disclosed.

\section{I confirm that I have read this submission and believe that I have an appropriate level of expertise to confirm that it is of an acceptable scientific standard, however I have significant reservations, as outlined above.}

Author Response 05 Feb 2015

Joseph Kraus, University of Denver, Denver, CO, USA

Thank you very much for the comments. I will take your response into consideration for the updated version of the article.

Competing Interests: No competing interests were disclosed.

Reviewer Report 21 November 2014

\section{https://doi.org/10.5256/f1000research.5589.r6619}

(C) 2014 Vandegrift $\mathbf{M}$. This is an open access peer review report distributed under the terms of the Creative Commons Attribution License, which permits unrestricted use, distribution, and reproduction in any medium, provided the original work is properly cited.

\section{Micah Vandegrift}

Strozier Library, Florida State University, Tallahassee, FL, USA

This article provides a helpful overview of the state of open access in the UK. Coming from a similar perspective as the author (working in scholarly communication at a university in the US), the focus of this piece was helpful to consolidate what often sounds like a lot of momentum toward open access from the UK. Between the title and the abstract, I was expecting a different paper than was presented; for example, perhaps a more appropriate title would be "Cash, carrots and sticks: A Survey of Recent Developments in Open Access in the United Kingdom."

Extrapolating from the abstract, I had hoped the article would begin with the UK, but also include the "international perspectives on scholarly communication issues" from Australia, Latin America and Asia. 
The organization of the paper could be improved by grouping sections a little differently. I see 3 major sections in the work, Intro/background context, Current Topics in ScholComm, and Survey/Results. "The Overview of OA developments" could easily be appended to the Introduction section, followed by a top level heading introducing all the "current topics" around which the author constructed the survey: The Finch Report, RCUK, Green vs. Gold, Megajournals, prestige in open access, open access and scholarly societies, and altmetrics vs impact factor. I agree completely with the author that these topics are absolutely at the core of the current scholcomm conversation. Finally, a new section could follow titled Survey, Methodology and Analysis of Responses wherein the author synthesizes the survey responses referring to the context and current issues as necessary. Then, of course, close the paper with a conclusion. Reorganizing the paper would go a long way toward making its findings more digestible and impactful.

In many of the responses to the survey questions, the author uses the word "many" or "most." Every time I read that I wondered, does that mean $50 \%, 75 \%$ or $90 \%$ ? Even with the small sample size numerically representing the responses would be helpful. Also, including the question in the text of the article as it was written in the survey instrument makes the article read choppily. I'd prefer to read the question written into prose with the responses; for example, "When asked of their opinion on the ride and impact of megajournals like PLoSOne, 15/16 respondents agreed that this type of publishing will grow in popularity in the future."

The conclusion could be stronger by changing its focus from detailing each issue (green v. gold, megajournals, societies, etc.) to offering the author's perspective on why or why not the UK seems to be more forward-thinking in terms of open access policy at the governmental level. What is the author's "more nuanced understanding of the OA landscape"? Further, I'd love for the author to propose how this study might be replicated, extended, and expanded to a broader international scope. My own personal perspective is that a global view of how and why open access has real affects is absolutely necessary for the growth of this sub-field of librarianship. The promise of this article to provide an "international perspective" is exactly what we need. I'll push the author and those reading this piece to work toward that goal.

Competing Interests: No competing interests were disclosed.

\section{I confirm that I have read this submission and believe that I have an appropriate level of expertise to confirm that it is of an acceptable scientific standard.}

Author Response 05 Feb 2015

Joseph Kraus, University of Denver, Denver, CO, USA

I appreciate your comments and the recommendations you provided. I will take your response into consideration for the updated version of the article.

Competing Interests: No competing interests were disclosed. 


\section{Comments on this article}

\section{Version 1}

Reader Comment 12 Nov 2014

F1000 Research, UK

We really appreciate your feedback. In response to the points about the formatting:

Unlike preprint servers, we publish all articles on the F1000Research platform fully published (as opposed to pre-prints) in standard article formats - HTML and PDF - used by traditional journals. We therefore don't display line numbering. If readers and referees wish to comment on specific areas of text we recommend they use the PDF of the article (available to download from the bar at the top of the article) and refer to pages, columns, and/or paragraphs.

(Elle Begg, editorial assistant)

Competing Interests: No competing interests were disclosed.

Reader Comment 11 Nov 2014

Philip Young, Virginia Polytechnic Institute and State University, USA

Thanks to Joseph Kraus for posting this early version for comment, something that ought to be happening far more frequently in library and information science. Your initiative inspired me to register and provide the following comments.

1. The title does not seem as aligned with the paper's content as it could be. Although incentives are addressed, it does not seem to be the primary subject of the paper. In addition, policies or mandates may not be considered incentives, though perhaps I misunderstand UK policy.

2. More details would be welcome about how you carried out these interviews. How were the interviewees selected? Did you know them personally? Were interviews conducted by email, phone, or in person? What disciplines did they represent?

3. Near the end of the introduction, you say "Many scholars are concerned about the rise of the open access megajournals, such as PLOS ONE." But this statement is not supported either by your summary, "Most of the interviewees saw the rise of new magajournals as a positive development," or by the responses in the appendix. (3a: see typo "magajournals").

4. In Appendix 1, you list question 7. Were there any responses, and if so, where are they?

5. Combining UK and European interviewees seems to confound the original focus on UK 
policy, though perhaps they were all knowledgeable. I don't feel that I know much more about Finch/RCUK after reading this, and it might have been more informative to focus on US/UK differences and their implications rather than asking broader questions about altmetrics and scholarly societies. Given the general nature of the responses, in the future it might be more useful to make the questions more specific, and perhaps include some yes/no or Likert scale questions. In the end it is difficult for this reader to determine how these international perspectives inform a U.S. perspective.

6. In several places, the article's tone seems too informal. For example, in the conclusion you say that new communication methods are "popping up all the time". I think you could improve this paper by replacing these phrases with more professional language.

To F1000Research: it would be very helpful for readers if you supplied line numbers or other referencing system.

Competing Interests: No competing interests.

The benefits of publishing with F1000Research:

- Your article is published within days, with no editorial bias

- You can publish traditional articles, null/negative results, case reports, data notes and more

- The peer review process is transparent and collaborative

- Your article is indexed in PubMed after passing peer review

- Dedicated customer support at every stage

For pre-submission enquiries, contact research@f1000.com 